\title{
IMPACT OF DIFFERENT PLATELET CONCENTRATES APPLICATION ON BONE REGENERATION. AN EXPERIMENTAL STUDY
}

Ahmed El-Kabbaney *, Sally Elsayed Abdelsameaa ${ }^{* *}$ and Mohamed Abdulrahman***

\begin{abstract}
Purpose: This experimental study was to evaluate and compare bone regeneration capacity of experimental bone defects filled with different autologous platelet concentrates (APCs) as a bone graft material in the rabbit's tibiae.
\end{abstract}

Material and methods: A total of forty-two adult rabbits were included in this study. After creation of bone defects, the animals were randomly assigned to three groups. In control group, no bone graft was used (Group A, n=14), in one test group Plasma Rich in Growth Factors (PRGF) was used as bone graft material (Group B, n=14), and in the other test group Injectable Platelet Rich Fibrin (i-PRF) was used as bone graft material (Group C, n=14). After implantation, each group was further divided into two subgroups, where rabbits were sacrificed 2 and 4 weeks postoperatively and the defects were evaluated with histologic and histomorphometric analysis.

Results: Both test groups (Group B and Group C) treated with APCs (PRGF: $10.92 \pm 0.85$ $\& 41.53 \pm 2.55$ and i-PRF: $13.13 \pm 0.68 \& 57.27 \pm 1.66$ at 2 and 4 weeks respectively) demonstrated higher percentages of new bone formation than the control group $(5.11 \pm 1.15 \& 30.31 \pm 1.29$ at 2 and 4 weeks respectively) $(\mathrm{P}<0.001)$. Significant difference was found between the two test groups and control group $(P<0.001)$. On the other hand, significant difference was found between test groups $(P<0.001)$.

Conclusions: Within the limitation of this animal study, the adjunct implication of either i-PRF or PRGF in endodontic surgery may be of great significance as it dramatically improves bone regeneration.

KEYWORDS: Autologous Platelet Concentrates, Bone Regeneration, Endodontic Surgery.

* Lecturer of Endodontics, Faculty of Dentistry, Mansoura University, Mansoura, Egypt.

** Lecturer of Oral Surgery, Faculty of Dentistry, Mansoura University, Mansoura, Egypt.

*** Associate Professor of Oral Biology, Faculty of Dentistry, Mansoura University, Mansoura, Egypt. 


\section{INTRODUCTION}

Endodontic Surgery (also termed apicectomy, peri-apical surgery, peri-radicular surgery, surgical re-treatment) should be considered as the last option that any dentist should be able to perform to save a tooth before extraction. Following this surgery, a consecutive series of reactions including clotting, inflammation, granulation tissue formation, collagen synthesis and tissue remodeling are involved during the complex healing process. However, the factors that delay or hinder it are fields of interests by many scientists. ${ }^{(1,2)}$ Guided tissue regeneration using different bone grafting materials and/or membrane barriers following peri-radicular tissue destruction by pathological processes, has a major role on the success of endodontic surgery. ${ }^{(3)}$

Guided tissue regeneration (GTR) is an updated technique(s) for regeneration of specific periodontium tissues that have been damaged by either periodontal or pulpal diseases by focusing on improving and directing cell growth. ${ }^{(4)}$ The main application of GTR principles in endodontic surgery was to reestablish damaged bone and periodontal tissues by placing various bone filling biomaterials and/or different barrier membranes. Excluding faster epithelial cells (ten times) from migration to the wound site as long as possible is the first concept that GTR was based on. Therefore, other cell types with regenerative potential (as osteoblasts), become settled, established and finally, tissue regeneration could be successfully achieved with the use of various barrier membranes and/or bone grafts. $(5,6)$ The purpose of a "space making technique" application in endodontic surgery is similar to those in implantology and periodontology: (A) creating favorable environment (stable and protected wound) for stimulating tissue regeneration; and (B) exclude non-desired fast-proliferating cells that hinders favorable tissue regeneration. ${ }^{(7)}$

In recent years, autologous platelet concentrates (APCs) have been used widely in oral surgical procedures as filling material for the bony defect instead of bone aiming at their ability to enhance the normal healing rate during bone regeneration procedures because of their high content in growth factors and cytokines such as transforming growth factors (TGF- $\beta$ ), vascular endothelial growth factor (VEGF), platelet-derived growth factor (PDGF), platelet activating factor-4 (PAF-4), epithelial cell growth factor (EGF), and basic fibroblast growth factor (bFGF). All of these growth factors play a significant role in the process of wound healing, improving tissue vascularity, and bone regeneration. $(8,9)$

Platelet rich plasma (PRP) is the first generation of autologous platelet concentrate used for tissue regeneration purpose. (10,11) Although it had shown success clinical rate, its complexity during preparation protocol which increases the cost, duration and the complexity of the surgical procedure in face of relatively moderate benefits, restrict its applications in regenerative surgical procedures. (12,13) A subsequent technique was developed to prepare second generation of autologous platelet concentrate, which is Plasma Rich in Growth Factors (PRGF) System. This system proved to offer many advantages over conventional (PRP) such as the fact that it is less time consuming, no bovine thrombin required for activation, less venous blood is needed, the product is free from inflammatory interleukins and white blood cells and may be directly performed with one step centrifugation. In addition, it allows preparation of both PRGF gel and fibrin membrane at the same time. ${ }^{(12)}$

Platelet rich fibrin (PRF), invented and launched by Choukroun et al. in the year 2001, is a thirdgeneration of platelet concentrates rich in platelets and growth factors which enhance bone regeneration and healing. PRF preparation protocol is different from PRP and PRGF, as it is prepared from blood sample without anticoagulant or thrombin making it safer and risk free of infection or disease 
transmission. ${ }^{(14)}$ In 2014, a novel platelet concentrate, a liquid injectable-platelet-rich fibrin (i-PRF) was developed by modifying spin centrifugation forces. Its concept is based on slowing down the fibrin coagulation at early time points by lowering the centrifugation speeds and by utilizing non-glass centrifugation tubes, thus generating an injectablePRF. Much like traditional PRF, i-PRF contains an increased number of leukocyte and is further able to stimulate release of growth factors. ${ }^{(15)}$

Since the efficacy of platelet concentrates in improving hard tissue healing is still debated because contrasting results have been reported by different studies. ${ }^{(16-19)}$ Thereby, it may be of great value to evaluate and compare between the impact of Plasma Rich in Growth Factors (PRGF) System and Injectable Platelet Rich Fibrin (i-PRF) on bone regeneration capacity of experimental bony defects in rabbits' tibiae.

\section{MATERIALS AND METHODS}

\section{Animals and anesthesia}

Healthy forty-two adult rabbits (white New Zealand race, age 6 months, weighing between 1.5$2 \mathrm{~kg}$ were selected in the study. For acclimatization, rabbits were kept for one week before the onset of experiment and housed at room temperature $25^{\circ} \mathrm{C}$, 12 hours light dark cycle and relative humidity of $65-70 \%$ was kept constant in the research laboratory of the Nile Center for Experimental Research, Mansoura, Egypt. Water and food were allowed to rabbits ad libitum. They were fed green paper and dry bread. All experimental procedures were done under accepted protocol of ethical committee of Faculty of Dentistry, Mansoura University, Egypt.

For each animal, the same anesthetic protocol was administered, which ensures full animal unconsciousness during surgical procedures and an excellent degree of pre-operative analgesia. All animals included in this study were anaesthetized using intramuscular injection Diazepam* $(0.5 \mathrm{mg} / \mathrm{kg}$ body weight), and Ketamine hydrochloride ${ }^{* *}(20 \mathrm{mg} / \mathrm{kg}$ body weight). Also, the region of surgery was injected locally with anesthetic solution of 2\% Mepivacaine $\mathrm{Hcl}$ with 1:20,000 Levonordine ${ }^{* * * *}$. Anesthesia was injected in the proximal right tibia.

\section{Surgical procedure}

Under general anesthesia, all animal hair on the medial aspect of the right tibia was shaved, followed by disinfection of the skin surface at this area which was done by povidone iodine ${ }^{* * * *}$ solution before the operation. $3 \mathrm{~cm}$ longitudinal incision was made over the medial aspect of each animal's tibia, skin was dissected till bone was exposed. In each tibia, a cylindrical critical sized bone defect, about $4 \mathrm{~mm}$ in diameter and $1 \mathrm{~mm}$ in depth was created using a surgical trephine bur mounted on oral implant handpiece. The size and depth of bone defects were standardized by using the same size of trephine bur head at the same speed. The bone was continuously irrigated with sterile saline during cutting to reduce thermal damage. The forty-two rabbits were randomly divided into 3 groups $(n=14)$ according to the type of bone graft material as the following:

- Group A: The bony defect received no bone graft material to serve as control group.

- Group B: The bony defect was filled with PRGF

- Group C: The bony defect was filled with i-PRF.

Bone defects allocated to the group B were filled with plasma rich in growth factor (PRGF) in a ratio of $2 \mathrm{~g} / 0.5 \mathrm{ml}$. The platelet concentrate was obtained by centrifugation* (at $460 \mathrm{~g}$ for 8 minutes) of $5 \mathrm{ml}$ of

\footnotetext{
* Neuril: manufactured by Memphis Co. For Pharm \& Chemical ind. Cairo, Egypt.

** Ketamine hydrochloride: manufactured by ketalht, amourr Co, Cairo, Egypt

*** Mepecaine-L: manufactured by Alexandria Co, Egypt.

**** Betadine: manufactured by Nile Co, Cairo, Egypt.
} 
fresh blood collected from the animal marginal vein of the ear into tubes containing 3.8\% anticoagulant (sodium citrate). After centrifugation, the plasmatic component was separated into 2 fractions by using a laboratory pipette. The lower fraction of about 1 $\mathrm{mL}$, immediately above the buffy coat, is the PRGF. Immediately before filling the bone defect, the PRGF was activated with calcium chloride $10 \%$ in the amount of 50 microliters / $\mathrm{ml}$ PRGF to enable clot formation. This allowed creating a gel with mechanical consistency that is stable and easy to handle. ${ }^{(20)}$

Bone defects allocated to the group $\mathrm{C}$ were filled with Injectable Platelet rich fibrin (i-PRF). Blood was drawn as in group B and by using sterile uncoated $9 \mathrm{ml}$ plastic tubes, $5 \mathrm{ml}$ of whole blood without anti-coagulant was centrifuged at $700 \mathrm{rpm}$ and $60 \mathrm{~g}$ for 3 minutes. The upper liquid layer was collected as i-PRF. ${ }^{(21)}$

The incisions were closed using 4/0 black silk attached to a curved needle $3 / 8$. The sutures were removed after 9 days for prevention of infection. All the animals were subjected to post-surgical analgesia with $10 \mathrm{mg} / \mathrm{kg}$ (Brufen suspension)*** orally every 4 hours for 4 days. Moreover, antibiotic therapy was administered ((Enrofloxacin ${ }^{* * * *} 2.5 \%$ at a dose of $10 \mathrm{mg} / \mathrm{kg}$ orally every 12 hours for 5 days). The rabbits recovered in a cage with one animal per cage.

During the follow up periods, all the rabbits were under frequent surveillance by the Department of Mansoura Experimental Research Center in the same housing conditions described above and periodically visited to identify early any pain attitudes or clinical signs of malaise. The following are possible signs that may have been associated with pain in the rabbits.: Abnormally "hunched" appearance when sitting; alert but reluctant to move; Limping; Unusual or sudden aggression; loss or decrease in appetite or water consumption; tooth grinding; shows no interest in the surroundings (loss of curiosity); crying or "grunting" when oving/ defecating/urinating or being handled/examined; taking a long time to eat; dropping food out of the mouth. If they had identified any of these attitudes, the veterinarian would immediately initiate a treatment therapy to the problem, or if it had not been any viable treatment option, euthanasia would be proceeded. The only significant event recorded during this period, was leg fracture of one of the rabbits three days after surgery; the animal was promptly subjected to euthanasia (using standard procedure described below) and replaced with another rabbit, which has been practiced the same treatment.

\section{Evaluation}

For postoperative evaluation, each group was further divided into two subgroups and seven rabbits in each group were euthanized at each of the experimental periods 2 and 4 weeks postoperatively by overdose of diethyl ether. Then bone blocks were dissected in correspondence to the treated areas, by means of a surgical bur without encroaching on the grafted areas.

\section{Histological analysis}

For subsequent histological and histomorphometric analysis, the dissected specimens were fixed immediately in $10 \%$ formal saline solution for 48 hours. Then all samples were treated with $10 \% \%$ Ethylene Diamine Tetra Acetic acid (EDTA) decalcifying solution. Samples were dehydrated with

\footnotetext{
* TC-SPINPLUS-6 Digital Desktop Centrifuge with 3074 RCF, 100-5000 rpm, LCD Display, Includes 15ML X 6 Rotor, Timer 15sec-99min, Topscien, Ningbo, China.

** Brufen : Kahira Pharmaceuticals \& Chemical Industries Company.

*** Enrofloxacin 10\%: produced by EL Nasr Pharmaceutical Chemicals Co, Abu Zaabal- Egypt.
} 
alcohols and embedded in paraffin. Serial sections were made at $6 \mu$ thickness. Sections of specimens will be prepared for:

a) Meyer's Haematoxylin and Eosin stain (as routine histological stain).

b) Masson's Trichrome stains (for the detection of collagen).

- Histomorphometric analysis: Computer assisted digital image analysis was applied on the trichrome stained sections

Histomorphometric analysis of the newly formed bone carried out using Olympus ${ }^{\circledR}$ digital camera installed on Olympus ${ }^{\circledR}$ microscope with $1 / 2 \mathrm{X}$ photo adaptor; using $100 \mathrm{X}$ objective. Then the result images were analyzed on Intel ${ }^{\circledR}$ Core $\mathrm{I} 3 \AA$ based computer using Video Test Morphology® software (Russia) with a specific built-in routine for stain quantification and area measurement. Pathologists were blinded to the graft material and the time period for each sample.

\section{Statistical Analysis}

Data analysis was done using IBM SPSS Corp. Statistics for Windows, Version 22.0. Armonk, NY, USA. Qualitative data were described using number and percent. One Way ANOVA test was used to compare bone formation between studied groups with Post Hoc Tukey test to detect pair-wise comparison. A probability of $\mathrm{P}=0.05$ indicates the level of significance.

\section{RESULTS}

\section{Histologic evaluation}

Histological results showed: After 2 weeks, new bone formation was observed in all groups.
Emerging young bony trabeculae were observed not only on the periphery of the defects, but also in their central parts. (Figure 1) After 4 weeks; In control group A, there was a discrete regeneration of newly formed bone trabeculae. While in group B, osteocytes were observed dispersed within the newly formed trabecular bone with Haversian system could be seen. While in group $\mathrm{C}$, a distinction is clear between old and newly bone with little amount of granulation tissue. (Figure 2)

\section{Histomorphometric evaluation}

According to the histomorphometric evaluation of bone regeneration, the mean percent of the osteogenesis at 2 and 4 weeks for group B and group $\mathrm{C}$ was significantly higher in comparison with control group A. In the control group A, there was a discrete regeneration with an average percentage of newly formed bone equal to $5.11 \pm 1.15 \& 30.31 \pm 1.29$ at 2 and 4 weeks respectively. In group B where PRGF was used, the newly formed bone was on average $10.92 \pm 0.85 \& 41.53 \pm 2.55$ at 2 and 4 weeks respectively. In group $\mathrm{C}$ where i-PRF was used, the newly formed bone was on average $13.13 \pm 0.68$ \& $57.27 \pm 1.66$ at 2 and 4 weeks respectively. (Figure

\section{3 \& 4)}

The descriptive statistics of histomorphometric data from all the three evaluated groups are shown in Table 1 and Figure 5. PRGF and i-PRF showed statistically significant increase in the amount of regenerated bone over control group at 2 and 4 weeks $(P<0.001)$. Also, the average area of bone formation represented significant difference between the PRGF and i-PRF groups at the two follow up intervals $(P<0.001)$. 


\section{Histological and histochemical results:}

\section{A- Histological results (Hematoxylin and Eosin stain):}

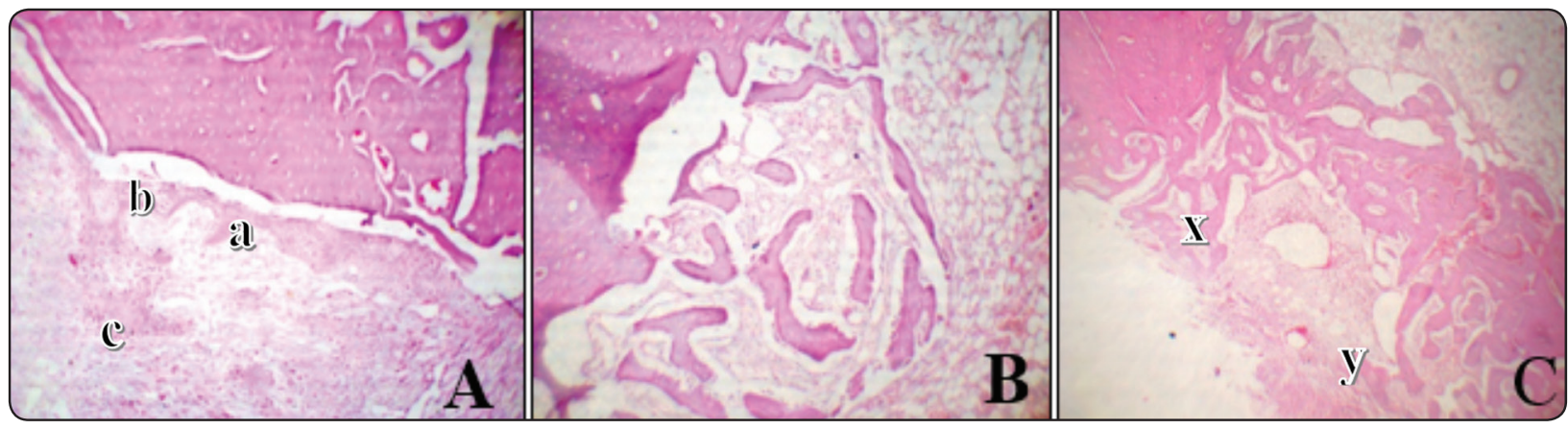

Fig. (1) Figure 1: After 2 weeks, A (control group): The cavity is filled with granulation tissues. Signs of newly formed bone trabeculae could be seen with faintly stain, $(\mathrm{a}, \mathrm{b})$. Osteoblastic activity is seen along the periphery of newly formed bone trabeculae (c). B (PRGF group): Multiple small bony trabeculae of different sizes and shapes could be seen inside the cavity surrounded by granulation tissues. C (i-PRF group): A network of bony trabeculae could be seen radiating from the upper and lower border of the cavity and directed toward the center of the cavity $(\mathrm{x}, \mathrm{y})$. The newly formed bone trabeculae could be distinguished easily from old bone.
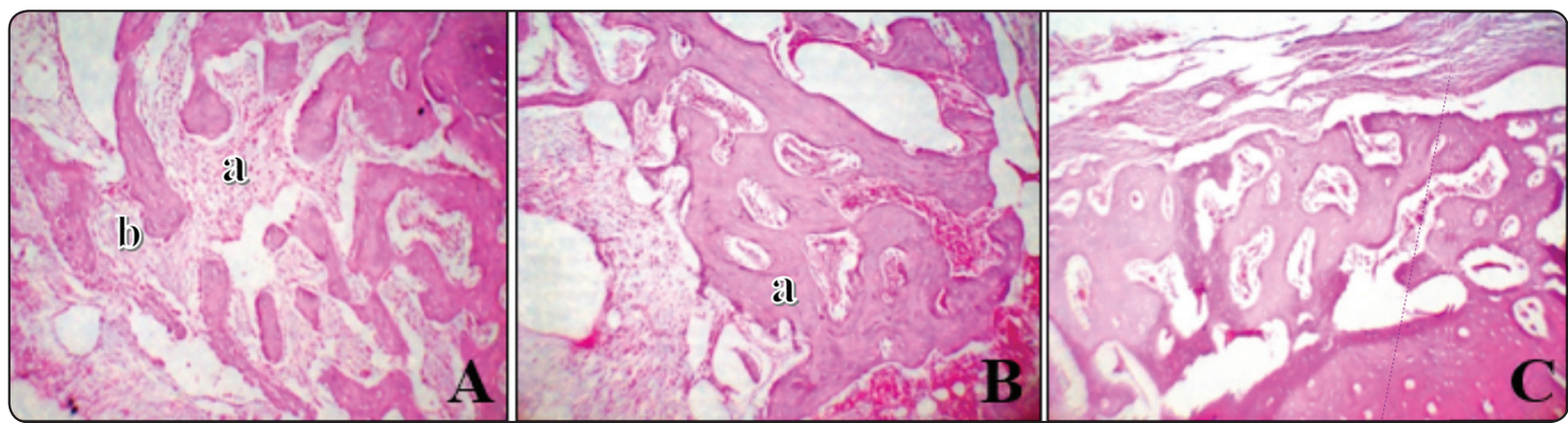

Fig. (2): After 4 weeks, A (control group): An interconnected bony trabecula is formed with intervening bone marrow cavity (a, b). B (PRGF group): A network of thick mature bone trabeculae with bone marrow cavities is seen easily. Osteocytes are seen dispersed inside bone segments. A sign of haversian system is noticed, (a). Granulation tissues are seen at the orifice of the cavity. C (i-PRF group): A network of mature bone trabeculae with minimizing the amount of granulation tissue is evident in the section.

\section{B-Histochemical results (Trichrome stain):}

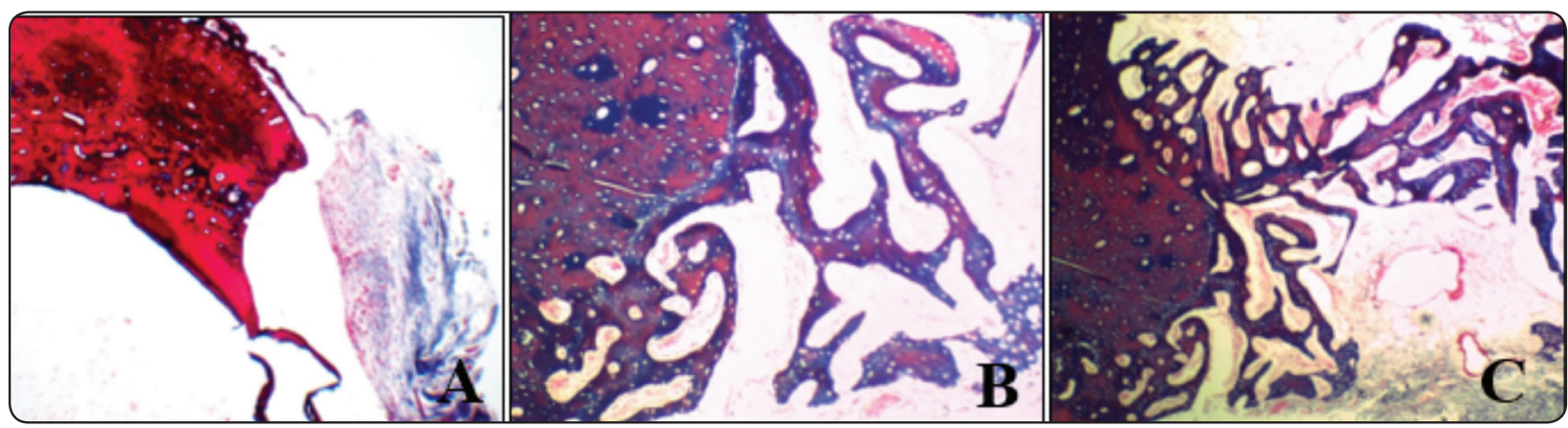

Fig. (3): After 2 weeks, A (control group): The section shows moderate reaction to trichrome stain. The reaction is restricted to the C.T. B (PRGF group): The section shows intense reaction. C (i-PRF group): The section shows intense reaction of the trabeculae and weak reaction of the C.T. 

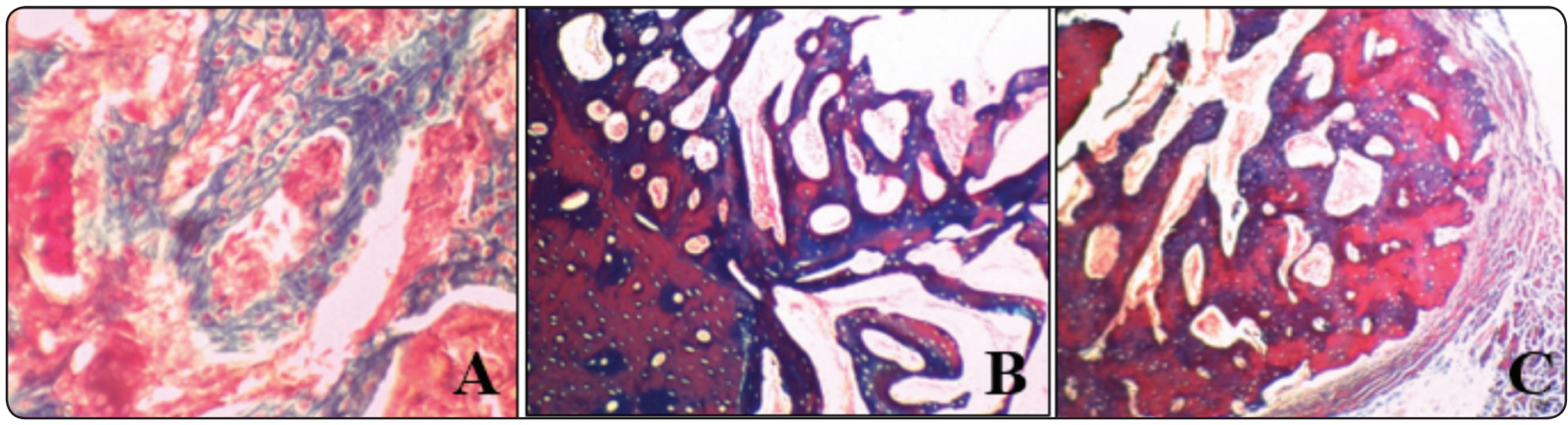

Fig. (4): After 4 weeks, A (control group): The section shows moderate reaction of the trabecula. B (PRGF group): The section shows severe reaction of the trabeculae. C (i-PRF group): The section shows intense reaction of the trabeculae

TABLE (1): Histomorphometric parameters (means and standard deviations of newly formed bone in each treatment group at $2 \& 4$ weeks intervals.

\begin{tabular}{|l|c|c|c|c|c|}
\hline Bone formation & Control group & PRGF group & i-PRF group & $\begin{array}{c}\text { Test of significance } \\
\text { (One Way ANOVA test) }\end{array}$ & $\begin{array}{c}\text { within group } \\
\text { significance }\end{array}$ \\
\cline { 2 - 6 } & $\mathrm{N}=7$ & $\mathrm{~N}=7$ & $\mathrm{~N}=7$ & $\mathrm{~F}=142.62$ & $\mathrm{P} 1<0.001 *$ \\
Week 2 & $5.11 \pm 1.15$ & $10.92 \pm 0.85$ & $13.13 \pm 0.68$ & $\mathrm{P}<0.001 *$ & $\mathrm{P} 2<0.001 *$ \\
Mean \pm SD & & & & & $\mathrm{P} 3<0.001 *$ \\
\hline Week 4 & $30.31 \pm 1.29$ & $41.53 \pm 2.55$ & $57.27 \pm 1.66$ & $\mathrm{~F}=352.46$ & $\mathrm{P} 1<0.001 *$ \\
Mean \pm SD & & & $\mathrm{P}<0.001 *$ & $\mathrm{P} 2<0.001 *$ \\
& & & & $\mathrm{P} 3<0.001 *$ \\
\hline
\end{tabular}

P1: Difference between control group and PRGF group, P2: difference between control group and i-PRF group, P3: difference between PRGF \& i-PRF groups, SD: standard deviation.

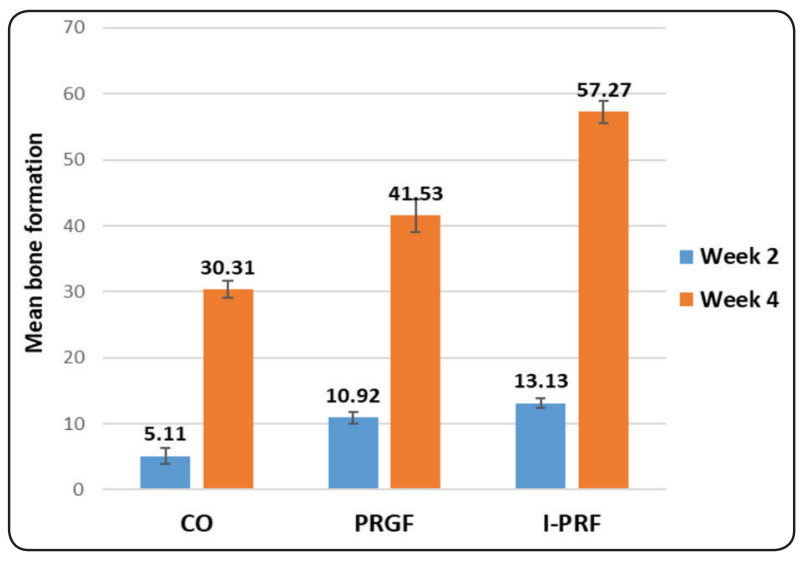

Fig. (5): Chart showing the average percentage of newly formed bone for the different experimental groups at the different time intervals.

\section{DISCUSSION}

Endodontic Surgery entail the creation of an osteotomy site, which normally has an uneventful healing process. In endodontic lesions, numerous regenerative approaches have been proposed for evaluation of bone regeneration in bone defects. ${ }^{(22-26)}$ which generally resulted in clinical improvement. In recent years, platelet concentrates (PCs) have gained significant acceptance as potential regenerative materials. A variety of preparation protocols have been introduced, (27) including Platelet rich Plasma (PRP) (Marx et al., 1998), ${ }^{(28)}$ Platelet-Rich Fibrin (PRF) (Choukroun, 2001), (29) and Plasma-rich 
Growth Factors (PRGF) (Anitua, 1999)..$^{(30)}$ The objective of the present animal study was to clarify whether the addition of PRGF and i-PRF would have a positive effect on bone regeneration in rabbit's tibiae compared to merely sealing the bone cavity without bone graft material.

(PRGF) identifies exclusively 100\% autologous blood derived product developed by a one-step centrifugation process, using sodium citrate and calcium chloride as anticoagulant and activator, respectively. It is safe, biocompatible, resorbed by the body within a few days after initiating local regeneration, and no risk of immunologic reactions as no bovine thrombin is used for activation. ${ }^{(31)} \mathrm{In}$ addition, this system prepares fibrin membrane that may be used as an autologous membrane for GTR. (32) In the fields of skin wound healing, repair of damaged tendon and cartilage, satisfactory results have been obtained. ${ }^{(33,34)}$

One of the latest developments in the PRF technology is the production of injectable PRF (i-PRF). Liquid PRF, which was prepared according to the low speed of centrifugation, has achieved predictable and effective results. The main difference of i-PRF from solid PRF is the lower speed and time in centrifugation for i-PRF. i-PRF is the liquid variety of PRF which may accelerate the wound-healing processes with increased vascularization. The benefits of i-PRF show slow and sustained release of growth factors, by releasing the expression of transforming growth factor- $\beta$ and collagen- 1 mRNA along with cells migration. ${ }^{(35)}$ It has advancement through injecting patients autologous PRF in indicated areas of bone, soft tissue, or skin. ${ }^{(36,37)}$

In our animal study, the histomorphometric evaluation of the amount of the newly regenerated bone showed that adding PRGF and PRF as bone graft materials to bone cavities caused a significant increase in bone regeneration at 2 and 4 weeks in comparison to control groups without bone graft material.

These findings agreed with other animal studies performed using platelet rich in growth factor (PRGF). ${ }^{(38-39)}$ On the other hand, it did not agree with animal study which was performed on dog. There was no statistically significant difference between the test and control group regarding the type of newly formed bone maybe because the PRGF has been used directly on the implants and the time of sampling was not similar. ${ }^{(40)}$

Our results agreed with Angerame et al. who studied the effect of PRF application around periradicular surgical defects on stimulating bone regeneration and reducing postoperative pain and reported promising results after 2 and 3 months. (41) This also comes in accordance with another study where the bony crypts during endodontic periradicular microsurgery were filled with platelet rich plasma (PRP) and Hydroxyapatite and reported faster bone healing compared to control group without bone grafts. ${ }^{(42)}$

However, our results disagreed with another clinical study that reported that the PRF application to the surgical cavity may not necessarily improve outcomes and showed no significant benefit regarding to bone healing when periapical surgery was done on perio-endo lesion with apico-marginal defects. ${ }^{(43,44)}$ This result may be due to periodontal communication that allow bacterial ingress from the marginal periodontium.

In our study, the i-PRF group showed significant increase in the amount of newly formed bone when compared to the PRGF group. This was in agreement with Wang et al. ${ }^{(15,45)}$ who evaluated osteoblast behavior by use of injectable PRF as compared to traditional PRP and found that i-PRF can induce higher cell migration. Injectable PRF showed higher messenger RNA levels of PDGF, TGF- $\beta$, type I collagen and fibronectin than PRP. This result was in contrast to Thanasut et al. who reported that Liquid PRF failed to promote bone 
regeneration on repairing alveolar cleft defect with autologous cancellous bone. ${ }^{(46)}$

This additional effect of i-PRF could be contributed to the lower centrifugation speed. Interestingly, two recent articles have further shown that in the upper layer where PRF is collected, a higher proportion of leukocytes could be found by decreasing centrifugation speeds, and thereby increasing total growth factor release. ${ }^{(47,48)}$ It may therefore be hypothesized that the additional incorporation of leukocytes as well as fibrin proteins that have yet to coagulate is one of the main reasons for the added benefit of i-PRF. ${ }^{(45)}$ Higher presence of regenerative cells with higher concentrations of growth factors can be observed when compared to other formulations of PRF utilizing higher centrifugation speeds. (21)

Finally, the present study recommends using of autologous platelet concentrates (APCs) either i-PRF or PRGF as a bone graft material in periradicular bone defects after endodontic surgery for enhancing bone regeneration. More histologic studies with larger sample sizes are required to confirm these findings.

\section{CONCLUSION}

Within the limitation of this animal study, the adjunct implication of either i-PRF or PRGF in endodontic surgery may be of great significance as it dramatically improves bone regeneration.

\section{RECOMMENDATIONS}

According to the results of the current study, it is recommended to use autologous platelet concentrates (APCs) either i-PRF or PRGF in periapical bony defects after endodontic surgery. Additional clinical and histologic studies with larger sample sizes and longer follow up rates are needed to confirm these results as high-level evidence supporting this approach is still sparse.

\section{ABBREVIATIONS}

APCs: autologous platelet concentrates

PRGF: plasma rich in growth factor

i-PRF: injectable platelet rich fibrin

\section{No conflict of interest.}

No funding was received for this study.

\section{REFERENCES}

1. Cedillo JA, Nakagoshi MA, Cepeda SS, Elizondo JE, Perez MT, Quintero EN et al. Alternative treatments to endodontic failure at different stages. Int J Appl Dent Sci 2020;6:34-38.

2. Locurcio LL, Leeson R. A case of periradicular surgery: apicoectomy and obturation of the apex, a bold act. Stomatological Dis Sci 2017;1:76-80.

3. Tuli M, Gangasani A, Mohammed Abdul MS, Kaur M, Gulia SK, Dharmi PR. Ideal tissue regeneration option following periapical surgery. J Dent Res Rev 2020; $7: 232-5$.

4. Karan NB, Aricioğlu B. Assessment of bone healing after mineral trioxide aggregate and platelet-rich fibrin application in periapical lesions using cone-beam computed tomographic imaging. Clin Oral Investig 2020; 24:1065-72.

5. Liu TJ, Zhou JN, Guo LH. Impact of different regenerative techniques and materials on the healing outcome of endodontic surgery: a systematic review and metaanalysis. Int Endod J 2020;6:1-20.

6. Sadiq S, Shetty P, Bhandary R, Bhat R. Treatment of Intrabony Defect Using Platelet Rich Fibrin Combined with Bioactive Glass: A Case Report of a Maxillary Central Incisor. Indian J Public Health Res Dev 2020;11:413-18.

7. Xu J, Gou L, Zhang P, Li H, Qiu S. Platelet-rich plasma and regenerative dentistry. Aust Dent J 2020;65:131-42.

8. Sanchez AR, Sheridan PJ, Kupp LI. Is platelet-rich plasma the perfect enhancement factor? A current review. Int J Oral Maxillofac Implants 2003;18(1):93-103.

9. Lindeboom JA, Mathura KR, Aartman IH, Kroon FH, Milstein DM, Ince C. Influence of the application of platelet-enriched plasma in oral mucosal wound healing. Clin Oral Implants Res 2007;18:133-9. 
10. Goyal B, Tewari S, Duhan J, Sehgal PK. Comparative evaluation of platelet-rich plasma and guided tissue regeneration membrane in the healing of apicomarginal defects: a clinical study. JOE 2011;37(6):773-780.

11. Freymiller EG, Aghaloo TL. Platelet-rich plasma: ready or not? J Oral and Maxillofac Surg 2004;62(4):484-488.

12. Dohan DM, Choukroun J, Diss A. Platelet-rich fibrin (PRF): a second-generation platelet concentrate. Part I: technological concepts and evolution. Oral Surg, Oral Med, Oral Pathol, Oral Rad and Endod 2006;101(3): E37-E44.

13. Anitua E, Andia I, Sanchez M. Plasma rich in growth factor. Dent Dialogue. 2004;3.

14. Anitua $E$. The use of plasma-rich growth factors (PRGF) in oral surgery. Pract Proced Aesthet Dent 2001;13:487-493.

15. Wang X, Zhang Y, Choukroun J, Ghanaati S, Miron RJ. Effects of an injectable platelet-rich fibrin on osteoblast behavior and bone tissue formation in comparison to platelet-rich plasma. Platelets 2018;29(1):48-55.

16. Alissa R, Esposito M, Horner K, Oliver R. The influence of platelet-rich plasma on the healing of extraction sockets: an explorative randomised clinical trial. Eur J Oral Implant 2010;3:121-34.

17. Simon D, Manuel S, Geetha V, Naik BR. Potential for osseous regeneration of platelet rich plasma: a comparative study in mandibular third molar sockets. Indian J Dent Res 2004;15:133-6.

18. Mozzati M, Martinasso G, Pol R. The impact of plasma rich in growth factors on clinical and biological factors involved in healing processes after third molar extraction. J Biomed Mater Res A 2010;95:741-6

19. Del Fabbro M, Bortolin M, Taschieri S. Is autologous platelet concentrate beneficial for post-extraction socket healing? a systematic review. Int J Oral Maxillofac Surg 2011;40:891-900.

20. Anitua E, Tejero R, Zalduendo MM, Orive G. Plasma rich in growth factors promotes bone tissue regeneration by stimulating proliferation, migration, and autocrine secretion in primary human osteoblasts. J Periodontol 2013;84(8):1180-90.

21. Miron RJ, Fujioka-Kobayashi M, Hernandez M, Kandalam U, Zhang Y, Ghanaati S et al. Injectable platelet-rich fibrin (i-PRF): opportunities in regenerative dentistry?. Clin Oral Investig 2017;21:2619-27.
22. Rankow HJ, Krasner PR. Endodontic applications of guidedtissue regeneration in endodontic surgery. JOE 1996;22:34-43.

23. Uchin RA. Use of a bioabsorbable guided tissue membrane as an adjunct to bony regeneration in cases requiring surgical intervention. JOE 1996;22:94-6.

24. Britain SK, Arx T, Schenk RK, Buser D, Nummikoski $\mathrm{P}$, Cochran DL. The use of guided tissue regeneration principles inendodontic surgery for induced chronic periodontic-endodontic lesions: a clinical, radiographic, and histologic evaluation. J Perio 2005;76:450-60.

25. Pitt Ford TR, Torabinejad M, McKendry DJ, Hong CU, Kariya-wasam SP. Use of mineral trioxide aggregate for repair of furcal perforations. Oral Surg Oral Med Oral Pathol Oral Radiol Endod 1995;79:56-63.

26. Bernabe PF, Holland R, Morandi R, de Souza V, Nery MJ, Otoboni Filho JA. Comparative study of MTA and othermaterials in retrofilling of pulpless dogs' teeth. Braz Dent J 2005;16:149-55.

27. Dragonas P, Schiavo JH, Avila-Ortiz G, Palaiologou A, Katsaros T. Plasma rich in growth factors (PRGF) in intraoral bone grafting procedures: A systematic review. J Craniomaxillofac Surg 2019 Mar;47(3):443-453.

28. Marx RE, Carlson ER, Eichstaedt RM, Schimmele SR, Strauss JE, Georgeff KR. Platelet-rich plasma: growth factor enhancement for bone grafts. Oral Surg Oral Med Oral Pathol Oral Radiol Endod 1998; 85(6):638e646.

29. Choukroun J. Une opportunite en paroimplantologie: le PRF. Implantodontie 2001;42: 55e62.

30. Anitua E: Plasma rich in growth factors: preliminary results of use in the preparation of future sites for implants. Int J Oral Maxillofac Implants 1999;14(4): 529e535.

31. Arora G, Arora S. Platelet-rich plasma-Where do we stand today? A critical narrative review and analysis. Dermatol Ther. 2021;34(1):e14343.

32. Sanchez M, Anitua E, Azorfa J, Andia I, Padilla S, Mujika I. Comparision of surgically repair achillus tendon tears using platelet-rich matrices. J Am J Sports Med 2007;35(2):245-51.

33. Aghaloo TL, Moy PK, Freymiller EG. Investigation of platelet rich plasma in rabbit cranial defects: A pilot study. J Oral Maxillofac Surg 2002;60(10):1176-81 . 
34. Wiltfang J, Schlegel KA, Schutze- Mosgau S, Nkenke E, Zimmermann R, Kessler P. Sinus floor augmentation with beta-tricalcium phosphate: does platelet-rich plasma promote its osseous integration and degradation? Clin Oral Implant Res 2003;14(2):213-8.

35. Agrawal DR, Jaiswal PG. Injectable Platelet Rich Fibrin (i-PRF): A Gem in Dentistry. Int J Cur Res Rev 2020;12(21):25.

36. Varela HA, Souza JC, Nascimento RM, Araujo RF, Vasconce $\neg$ los RC, Cavalcante RS et al. Injectable platelet rich fibrin: Cell content, morphological, and protein characterization. Clin Oral Investig 2019;23:1309-18.

37. Thanasrisuebwong P, Surarit R, Bencharit S, Ruangsawasdi N. Influence of Fractionation Methods on Physical and Biological Properties of Injectable Platelet-Rich Fibrin: An Exploratory Study. Int J Mol Sci 2019;20:1657.

38. Berglundh T, Lindhe J. Healing around implants placed in bone defects treating with Bio-Oss. An experimental study in the dog. Clin Oral Implants Res 1997;8(2):117-24.

39. Birang R, Torabi A, Shahabooei M, Rismanchian M. Effect of plasma-rich in plateletderived growth factors on periimplant bone healing: An experimental study in canines. Dent Res J 2012;9(1):93-9.

40. Paknejad M, Shayesteh YS, Yaghobee S, Shariat S, Dehghan M, Motahari P. Evaluation of the Effect of Plasma Rich in Growth Factors (PRGF) on Bone Regeneration. J Dent (Tehran) 2012;9(1):59-67.

41. Angerame D, De Biasi M, Kastrioti I, Franco V, Castaldo A, Maglione M. Application of platelet-rich fibrin in endodontic surgery: a pilot study. G Ital Endod 2015;29:51-7.
42. Vaishnavi C, Mohan B, Narayanan LL. Treatment of endodontically induced periapical lesions using hydroxyapatite, platelet-rich plasma, and a combination of both: An in vivo study. J Conserv Dent 2011;14:140-6.

43. Karan NB, Aricioğlu B. Assessment of bone healing after mineral trioxide aggregate and platelet-rich fibrin application in periapical lesions using cone-beam computed tomographic imaging. Clin Oral Investig 2020; 24:1065-72.

44. Liu TJ, Zhou JN, Guo LH. Impact of different regenerative techniques and materials on the healing outcome of endodontic surgery: a systematic review and meta-analysis. Int Endod J 2021;54(4):536-555.

45. Wang X, Zhang Y, Choukroun J, Ghanaati S, Miron RJ. The behavior of gingival fibroblasts on titanium implant surfaces in combination with either injectable-PRF or PRP. Int J Mol Sci 2017;18:331.

46. Thanasut A, Silkosessak O, Subbalekha K. Platelet-rich fibrin did not affect autologous bone graft in repairing alveolar clefts. Journal of Oral and Maxillofacial Surgery, Medicine, and Pathology 2021 Mar 3.

47. Fujioka-Kobayashi M, Miron RJ, Hernandez M, Kandalam U, Zhang Y, Choukroun J. Optimized Platelet Rich Fibrin With the Low Speed Concept: Growth Factor Release, Biocompatibility and Cellular Response. J Periodontol 2016:1-17.

48. Ghanaati S, Booms P, Orlowska A, Kubesch A, Lorenz J, Rutkowski J et al. Advanced platelet-rich fibrin: a new concept for cell-based tissue engineering by means of inflammatory cells. J Oral Implantol 2014;40(6):679-689. 